\title{
Electrochemical Studies of Meropenem at Glassy Carbon Electrode and its Direct Determination in Human Plasma by Square Wave Anodic Adsorptive Stripping Voltammetry
}

\author{
KRISHNA KUMAR JHANKAL and D. K. SHARMA* \\ Electrochemical Research Laboratory, Department of Chemistry, University of Rajasthan, \\ Jaipur (Rajasthan) -302004, India \\ sharmadkuor@gmail.com
}

Received 24 June 2016 / Accepted 15 July 2016

\begin{abstract}
In present study a sensitive and fast square wave anodic adsorptive stripping voltammetric method was developed for the trace analysis of antibacterial drug meropenem in human plasma at glassy carbon electrode. The oxidation of meropenem gave a well-defined peak in Britton Robinson buffer at glassy carbon electrode. The process was diffusion controlled. A linear response was obtained between $1.0 \times 10^{-7}$ to $4.0 \times 10^{-5} \mathrm{M}$ in aqueous media. The recovery studies were also achieved to check sensitivity and accuracy of the method. The proposed method was applied for the determination of meropenem in body fluids without any time-consuming extraction, separation, adsorption steps. The value of limit of detection (LOD) for human urine and human serum samples was found to be $2.27 \times 10^{-6} \mathrm{M}$ and $1.67 \times 10^{-6} \mathrm{M}$ respectively.
\end{abstract}

Keywords: Meropenem, Square Wave Anodic Adsorptive Stripping Voltammetry, Glassy Carbon Electrode, Antibacterial

\section{Introduction}

Meropenem (Scheme 1), chemically (4R,5S,6S)-3- [[(3S,5S)-5-dimethylcarbamoyl pyrrolidin-3-yl]- thio]-6-[(1R)-1- hydroxyethyl]-4-methyl-7-oxo-1- azabicyclo[3,2,0] hept2-ene-2-carboxylic acid, is a new parenteral carbapenem antibiotic with a very broad spectrum of antibacterial activity against the majority of gram-positive and gram-negative pathogens ${ }^{1}$. It is more active in vitro than imipenem against Enterobacteriaceae and Pseudomonas aeruginosa, but less active against gram positive $\operatorname{cocci}^{2}$. This antibiotic has shown clinical efficacy in the treatment of a wide range of serious infections such as intraabdominal infections, urinary tract infections and lower respiratory tract infections including patients with cystic fibrosis ${ }^{3,4}$. 


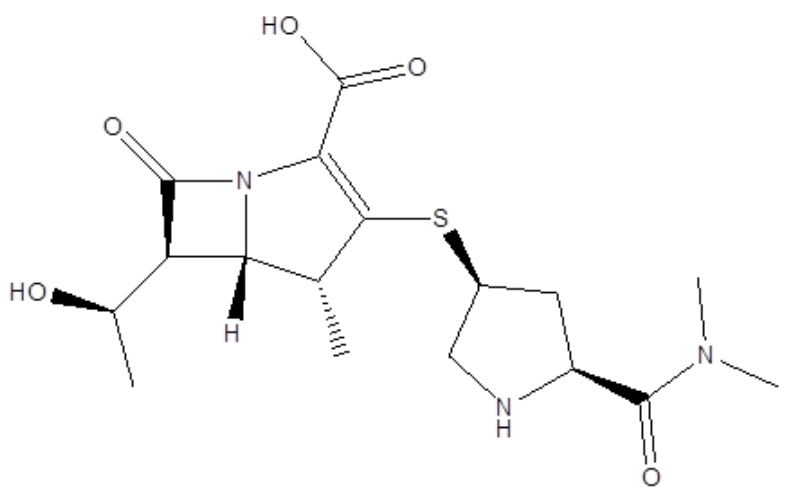

Scheme 1. Chemical Structure of Meropenem

A survey of literature has revealed several analytical methods for the determination of meropenem and its main metabolite (ICI-213689) in biological fluids, including highperformance liquid chromatography (HPLC $^{5-8}$, capillary zone electrophoresis ${ }^{9-10}$ and microbiological assay ${ }^{11}$.

Electroanalytical methods have long been used for the determination of a wide range of drug compounds due to their simplicity, low cost and relatively short analysis time when compared to other techniques. Additional application of electrochemistry includes the determination of electrode mechanism. Redox properties of organic molecules can give insights into their metabolic fate or their in vivo redox processes or pharmacological activity. Such use of electroanalytical measurements has found a vast of applications, including environmental monitoring, determination of a wide range of drug compounds, industrial quality control or biomedical analysis ${ }^{12-23}$.

Electrochemical determination of meropenem with doripenem by modified electrode is available in literature ${ }^{24}$. To date no electrochemical method is available in literature for determination of meropenem in human plasma by square wave stripping mode. In present study, a validated Square Wave Anodic Adsorptive Stripping Voltammetry (SWAAdSV) method was described for determination of meropenem in spiked human urine and serum samples.

\section{Experimental}

Meropenem was provided by Cipla India Pvt. Ltd. and was used without further purification. A stock standard solution of bulk meropenem $\left(1 \times 10^{-4} \mathrm{M}\right)$ was prepared in water and stored at $4{ }^{\circ} \mathrm{C}$ until assay. The Working solutions were prepared daily by appropriate dilution of the standard solution of bulk Meropenem just before use. A series of BR buffer of $\mathrm{pH}$ values 3 to 11 was prepared and used as a supporting electrolyte.

\section{Instrumentation}

Model 1230A (SR 400) electrochemical analyser (CHI Instrument, USA) was employed for electrochemical techniques, with a totally automated attached to a PC with proper CHI $100 \mathrm{~W}$ version 2.3 software for total control of the experiments and data acquisition and treatment. A three electrode cell system was used with activated glassy carbon electrode $(\varnothing=3 \mathrm{~mm}, \mathrm{CHI})$ as working electrode, $\mathrm{Ag} / \mathrm{AgCl}(3 \mathrm{M} \mathrm{KCl})$ as the reference electrode and a platinum wire as the auxiliary electrode. A magnetic stirrer (CAT.NO-1250-2 LAB-LINE 
INSTRUMENT, INC. USA) and a stirring bar provided the convective transport during the pre-concentration step. A digital pH-meter (CHINO- DB-1011) was used for measuring the $\mathrm{pH}$ values of the solutions investigated.

\section{Pre-treatment of the glassy carbon electrode}

The glassy carbon electrode was polished with $0.5 \mu \mathrm{m}$ alumina powder before each electrochemical measurement. Then it was thoroughly rinsed with methanol and double distilled water and gently dried with a stream of nitrogen gas.

\section{Analysis of spiked human urine and blood serum sample}

Drug-free human urine, obtained from healthy volunteers was centrifuged (4000 rpm) for 30 minutes at room temperature and separated sample were stored frozen until assay. An aliquot of urine sample $(1.0 \mathrm{~mL}$ each $)$ were fortified with various concentrations of meropenem $\left(1 \times 10^{-7}\right.$ to $\left.1 \times 10^{-5} \mathrm{M}\right)$ in centrifuge tubes then each was mixed with a $1.0 \mathrm{~mL}$ volume acetonitrile to denature and precipitate proteins. After vortexing for $30 \mathrm{~s}$, the mixture was then centrifuged for $10 \mathrm{~min}$ at $4000 \mathrm{rpm}$ in order to eliminate protein residues. Appropriate volumes of this sample were transferred into the voltammetric cell and diluted up to the volume with BR buffer and subsequently analyzed according to the recommended in the general analytical procedure. An aliquot of human serum sample was collected and analyzed as human urine sample.

\section{General analytical procedure}

$10 \mathrm{~mL}$ of the total solution containing BR buffer and the appropriate concentration of the Meropenem were transferred into the electrochemical cell, through which a pure deoxygenated nitrogen stream was passed for 10 minutes to remove the oxygen gas completely before measurements. The accumulation of meropenem at the working electrode was carried out for a selected time while the solution was stirred at $2000 \mathrm{rpm}$. The stirring was then stopped and after a rest period square wave stripping voltammograms was recorded in the anodic direction over the range 0.6 to $1.6 \mathrm{~V} v s . \mathrm{Ag} / \mathrm{AgCl} / \mathrm{KCl}$ reference electrode at room temperature. Cyclic voltammetric measurements were also carried out under similar conditions to investigate the reversibility of the redox process.

\section{Results and Discussion}

The electrochemical behaviour of meropenem was studied by cyclic voltammetry and square wave anodic adsorptive stripping voltammetric technique (SW-AAdSV) on glassy carbon electrode. In all electrochemical methods Meropenem gave one well defined oxidation peak in potential range $1.1 \mathrm{~V}$ to $1.2 \mathrm{~V}$ vs. $\mathrm{Ag} / \mathrm{AgCl} / \mathrm{KCl}$ reference electrode at glassy carbon electrode (GCE) in BR buffer at $\mathrm{pH} 6$.

\section{Cyclic voltammetric behaviour}

Cyclic voltammograms of meropenem were recorded within a wide range of the potential ( 0.6 to $1.6 \mathrm{~V}$ vs. $\mathrm{Ag} / \mathrm{AgCl} / \mathrm{KCl}$ reference electrode) at different $\mathrm{pH}$ values, scan rates and concentration. Meropenem gave one well defined oxidation peak, no peak were observed in the reverse scans, suggesting the irreversible nature of the electrode process (Figure 1).

\section{Effect of $p H$}

The influence of the $\mathrm{pH}$ on the oxidation process was studied and only one voltammetric peak was observed in the whole $\mathrm{pH}$ range. However, the best result with respect to sensitivity 
accompanied with sharper response was obtained with $\mathrm{pH}$ 6.0, so that it was selected for further experiments. Figure 2 show the variation of oxidation peak current $\left(i_{p}\right)$ with $\mathrm{pH}$ of the supporting electrolyte.

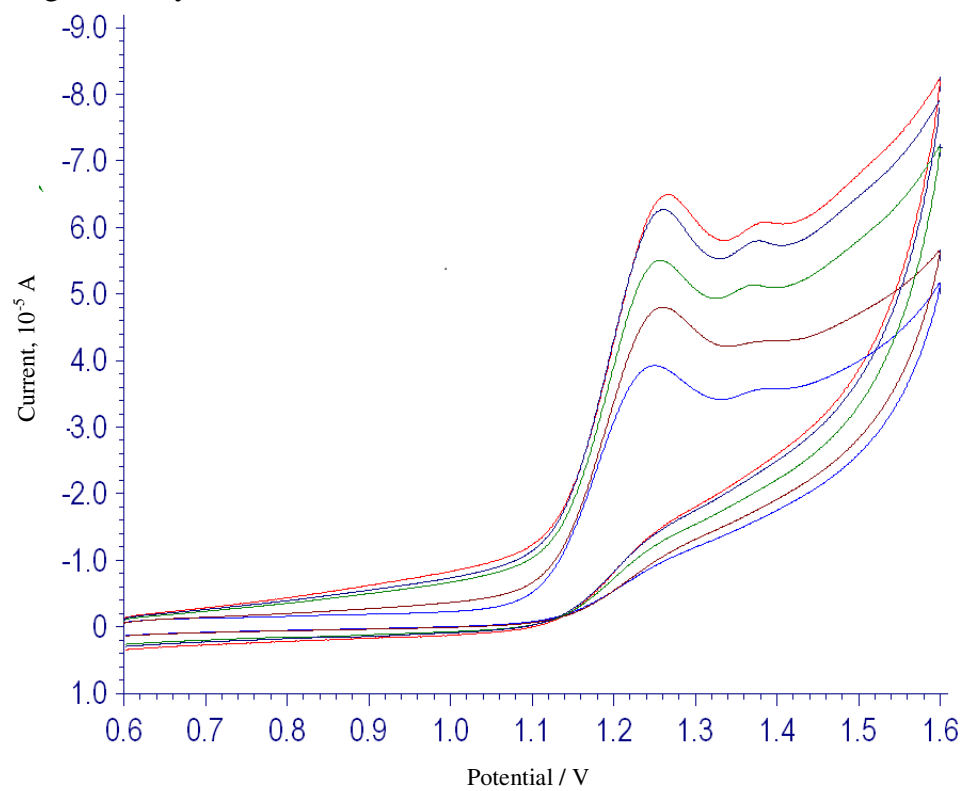

Figure 1. Cyclic voltammograms of $1.0 \times 10^{-4} \mathrm{M}$ meropenem at scan rates 50, 100, 150, 200, and $250 \mathrm{mV} / \mathrm{s}$ at GCE in BR Buffer of $\mathrm{pH} 6$

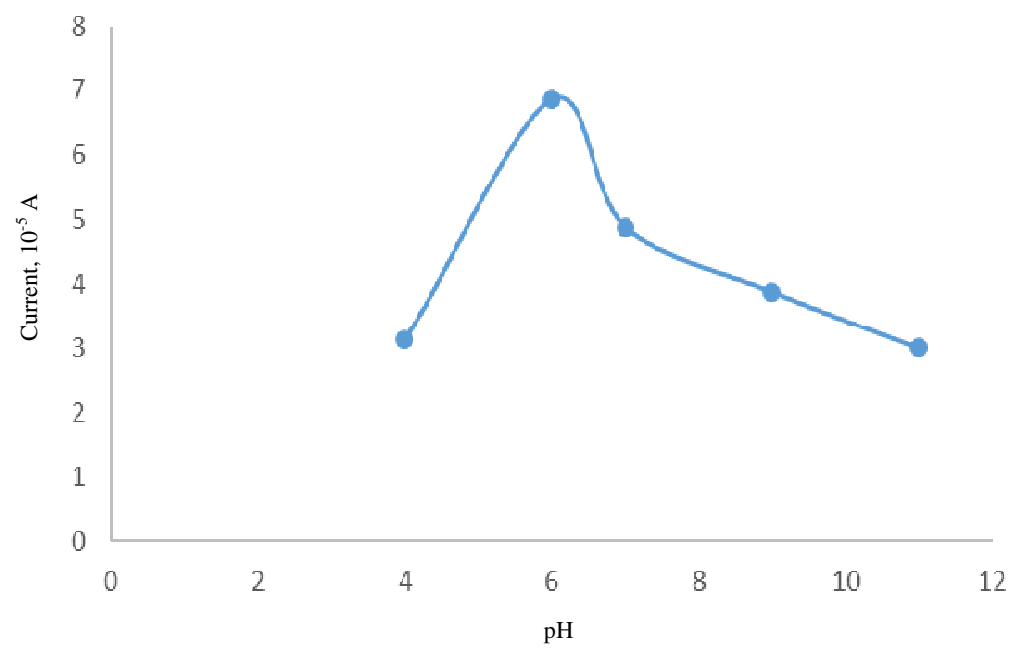

Figure 2. Plot of Peak current $\left(\mathrm{i}_{\mathrm{p}}\right)$ as a function of $\mathrm{pH}$ of the supporting electrolyte (BR Buffer)

\section{Effect of scan rate}

The cyclic voltamograms of $1.0 \times 10^{-4} \mathrm{M}$ meropenem were recorded at different scan rates at $25{ }^{\circ} \mathrm{C}$. Both peak potential and peak current are affected by scan rate. The whole procedure 
for cyclic voltammetry was repeated for meropenem with different scan rate ranging from 50 to $250 \mathrm{mVs}^{-1}$ while other parameter being kept constant. Graphs of peak potential $\left(\mathrm{E}_{\mathrm{p}} / \mathrm{V}\right)$ vs. $\log v\left(\mathrm{mVs}^{-1}\right)$ and peak current $\left(\mathrm{i}_{\mathrm{p}} / 10^{-5} \mathrm{~A}\right)$ versus square root of scan rates $\left(\mathrm{v} / \mathrm{mVs}^{-1}\right)^{1 / 2}$ were plotted.

The value of peak potential shifted towards more positive potential with the increase in sweep rate, which confirm the irreversibility of the process. For a totally irreversible electrode process the relationship between the peak potential $\left(\mathrm{E}_{\mathrm{p}}\right)$ and scan rate $v$ is expressed as $^{25}$ :

$$
E_{p}=E^{0}+\frac{2.303 R T}{a n F} \log \frac{R T k}{a n F}+\frac{2.303 R T}{a n F} \log v
$$

Where $E^{0}$ is the formal potential, $T$ the temperature, $\alpha$ is the transfer coefficient, $n$ is number of electrons involved in the rate determining step, $k$ is electrochemical rate constant and $F$ is the Faraday constant. A straight line was observed when peak potential $\left(\mathrm{E}_{\mathrm{p}} / \mathrm{V}\right)$ was plotted against $\log v(\mathrm{mV} / \mathrm{s})$ at a fix concentration and $\mathrm{pH}$ value of can be expressed as (Figure 3)

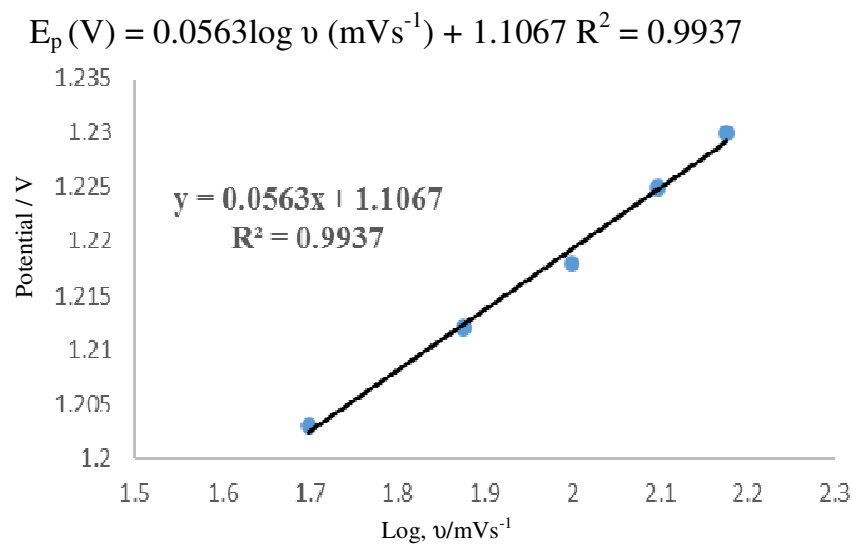

Figure 3. Plot of anodic peak potential $\left(\mathrm{E}_{\mathrm{p}} / \mathrm{V}\right)$ as a function of $\log v\left(\mathrm{mVs}^{-1}\right)$

For totally irreversible process, the peak current is given by Randel Sevcik equation:

$$
\mathrm{i}_{\mathrm{p}}=\left(2.99 \times 10^{5}\right) \mathrm{n}\left[\alpha \mathrm{n}_{\alpha}\right]^{1 / 2} \mathrm{ACD}^{1 / 2} v^{1 / 2}
$$

Where n $\alpha$ is the number of electrons taking part in the rate determining step of electrode process, $\alpha$ is electron transfer coefficient, $\mathrm{A}$ is apparent surface areaof the electrode, $\mathrm{C}$ is the concentration of the electro active species, D is the Diffusion Coefficient of the electroactive species and $v$ is the scan rate. The value $\alpha$, $\alpha$, as calculated from the slope is 1.049. Generally the value of $\alpha$ for totally irreversible electrode process is equal to 0.5 , Thus two electrons involved in the electro oxidation of meropenem. In the proposed method, the electro-oxidation of meropenem involves two electrons and two proton transfer process (Scheme 2).

Plot of the peak current $\left(i_{p}\right)$ versus square root of the scan rates $\left(v^{1 / 2}\right)$ is described by the given equation (Figure 4):

$$
\mathrm{i}_{\mathrm{p}}\left(10^{-5} \mathrm{~A}\right)=0.1094 \mathrm{v}^{1 / 2}\left(\mathrm{mVs}^{-1}\right)^{1 / 2}+0.3375 \mathrm{R}^{2}=0.999
$$

As the scan rate was increased from $50 \mathrm{mVs}^{-1}$ to $250 \mathrm{mVs}^{-1}$ at a fixed concentration of meropenem, (i) the peak potential shifted anodically, (ii) the peak current increased steadily and (iii) the peak current function $\left(\mathrm{i}_{\mathrm{p}} / \mathrm{AC} \mathrm{v}^{1 / 2}\right)$, exhibited nearly constancy. 


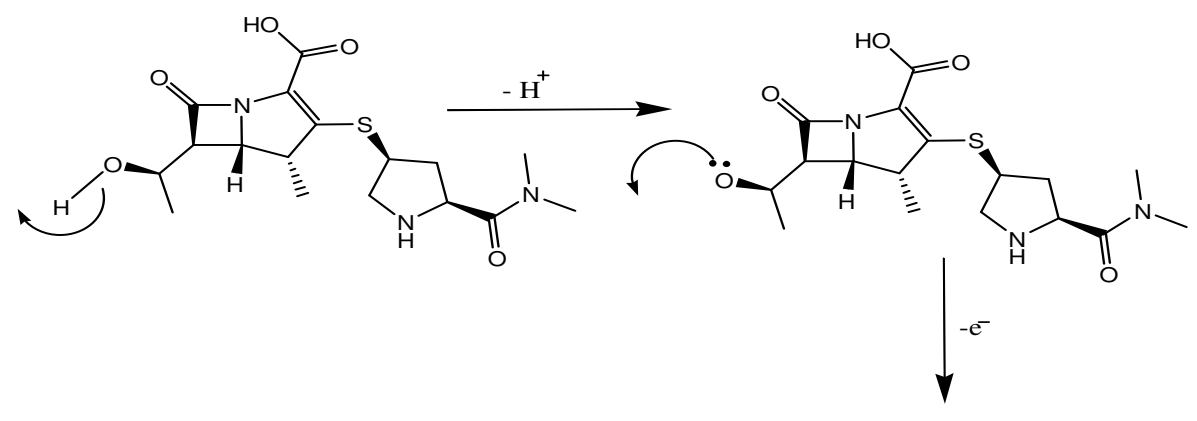<smiles>CCCC(C)(O)[C@H]1C(=O)N2C(C(=O)O)=C(S[C@@H]3CNC(C(=O)N(C)C)C3)[C@H](C)[C@]12[C@H](C)C(C)C</smiles>

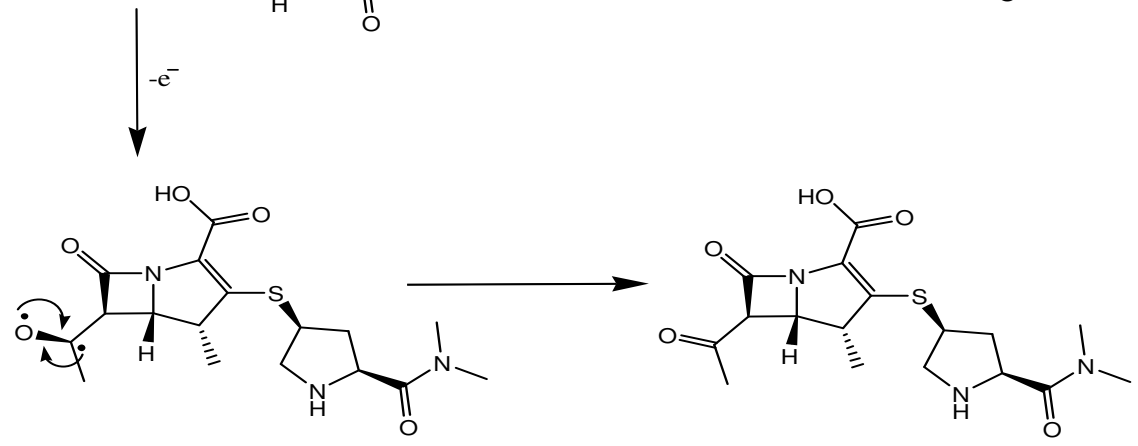

Scheme 2. Probable oxidation mechanism of meropenem

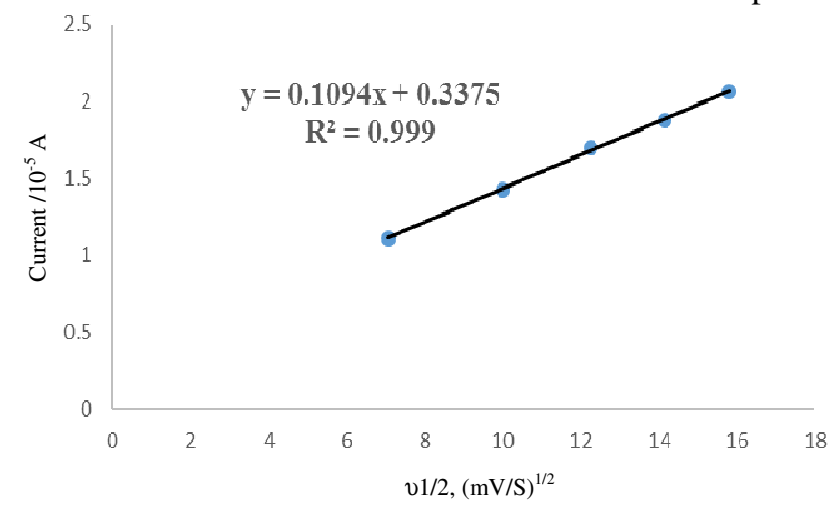

Figure 4. Plot of anodic peak current $\left(\mathrm{i}_{\mathrm{p}}\right) v s$ square root of scan rates $v^{1 / 2}\left(\mathrm{mVs}^{-1}\right)^{1 / 2}$

Square wave anodic adsorptive stripping voltammetric studies

For trace determination of meropenem square wave anodic adsorptive Stripping voltammetric (SWAAdSV) method was optimized. Stripping voltammograms of bulk meropenem in the BR buffer ( $\mathrm{pH} \mathrm{6)}$ were recorded by SW-AAdSV method following its 
pre-concentration onto the GCE by adsorptive accumulation for $30 \mathrm{~s}$. exhibited a welldefined single irreversible anodic peak with a better enhanced peak current magnitude at pH 6 . Quantitative evaluation of meropenem in human plasma is based on the linear correlation between the peak current and concentration. The graph of meropenem concentration vs. the peak current gave linear calibration curve indicating a diffusion-controlled process. The precision of the method was investigated by repeatedly $(n=5)$ measuring peak potential and peak current of meropenem within a day and over three consecutive days. LOD and LOQ were calculated by the following equations $\mathrm{s}^{25-28}$.

$$
\begin{aligned}
& \mathrm{LOD}=3 \mathrm{~s} / \mathrm{m} \\
& \mathrm{LOQ}=10 \mathrm{~s} / \mathrm{m}
\end{aligned}
$$

Where $\mathbf{s}$ is standard deviation of response and $\mathrm{m}$ is the slope of the calibration curve. LOD and LOQ values confirmed the sensitivity of the proposed methods, were shown in Table 1.

Table 1. Analytical parameters of meropenem drug by using SW-AAdSV method

\begin{tabular}{ccc}
\hline Parameters & Spiked human urine & $\begin{array}{c}\text { Spiked human blood } \\
\text { serum }\end{array}$ \\
\hline Concentration Range $(\mathrm{M})$ & $1 \times 10^{-6}$ to $4.0 \times 10^{-5}$ & $1 \times 10^{-6}$ to $4.0 \times 10^{-5}$ \\
Slope $(\mathrm{A} / \mathrm{M})$ & 0.14 & 0.1447 \\
Intercept $(\mu \mathrm{A})$ & 3.988 & 3.855 \\
Correlation Coefficient & 0.994 & 0.997 \\
LOD $(\mathrm{M})$ & $2.27 \times 10^{-6} \mathrm{M}$ & $1.65 \times 10^{-6}$ \\
LOQ $(\mathrm{M})$ & $7.56 \times 10^{-6} \mathrm{M}$ & $5.5 \times 10^{-6} \mathrm{M}$ \\
\hline
\end{tabular}

Assay of meropenem in spiked human urine and spiked blood serum samples

The proposed method SW-AAdSV was applied for the determination of meropenem in spiked urine samples of healthy volunteers, but not to urine samples of patients treated with meropenem. The recoveries from the urine samples were measured by spiking drug free urine with known amount of meropenem and square wave stripping voltammograms were then recorded (Figures 5A \& 6A). The amount of meropenem in the spiked urine samples were then evaluated from the calibration graph. The average recovery value, higher than $98.94 \%$ and RSD values less than $2.57 \%$, indicate the high accuracy and precision of the proposed method.

Further, the proposed method was also applied to the assay of meropenem in spiked human serum samples of healthy volunteers, but not to patient serum samples. For this experiment, drug free serum samples were spiked with different concentration of meropenem; square wave stripping voltammograms were then recorded. The amount of meropenemin each serum sample was calculated from the calibration curve (Figures 5B \& 6B). The calibration equations for meropenem in spiked human urine and spiked human serum can be written as;

$$
\begin{aligned}
& \mathrm{i}_{\mathrm{p}}(\mu \mathrm{A})=0.140 \quad \mathrm{C}(\mu \mathrm{M})+3.988 \quad \mathrm{R}^{2}=0.994 \\
& \mathrm{i}_{\mathrm{p}}(\mu \mathrm{A})=0.1447 \mathrm{C}(\mu \mathrm{M})+3.8555 \mathrm{R}^{2}=0.997
\end{aligned}
$$

The percentage recovery of drug was determined by comparing the peak currents of the drug in serum samples with those of pure drug with the calibration curve. Under the optimized condition a linear correlation between square wave stripping peak intensity and the drug concentration was obtained over the range $1.0 \times 10^{-6}-4.0 \times 10^{-5} \mathrm{M}$. The results show that the proposed method was successfully applied for the assay of meropenem in human plasma (Table 2). 
Table 2. Results of analysis of meropenem in spiked human urine and serum samples by SW-AAdSV method

\begin{tabular}{|c|c|c|c|c|}
\hline \multicolumn{5}{|c|}{ Urine Samples } \\
\hline Meropenem added, $\mu \mathrm{M}$ & $\mathrm{n}$ & Amount found, $\mu \mathrm{M}$ & Average Recovery, $\%$ & RSD, \% \\
\hline 200 & 5 & 198.52 & 99.26 & 2.57 \\
\hline 200 & 5 & 197.88 & 98.94 & 2.45 \\
\hline 200 & 5 & 199.82 & 99.91 & 2.25 \\
\hline & & Serum Samples & & \\
\hline 200 & 5 & 199.94 & 99.97 & 2.31 \\
\hline 200 & 5 & 198.02 & 99.01 & 2.28 \\
\hline 200 & 5 & 199.12 & 99.56 & 2.07 \\
\hline-1.6 & & & & \\
\hline-1.4 & & & & \\
\hline 1.2 & & & & \\
\hline$\underbrace{\varangle}_{0} 1.0$ & & & & \\
\hline 节 0.8 & & & & \\
\hline 己 0.6 & & & & \\
\hline & & & & \\
\hline-0.2 & & & & \\
\hline & 0.7 & $\begin{array}{llllll}0.8 & 0.9 & 1.0 & 1.1 & 1.2\end{array}$ & $\begin{array}{llll}3 & 1.4 & 1.5 & 1.6\end{array}$ & \\
\hline
\end{tabular}

Figure 5(A). Square wave anodic adsorptive stripping voltammograms of meropenem at different concentration in spiked human urine at $\mathrm{pH} 6$

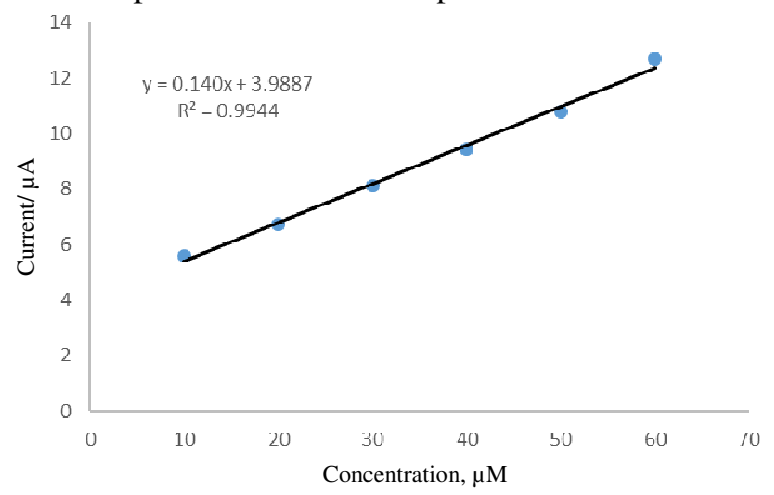

Figure 5(B). Plot of peak current $\left(i_{p} / \mu A\right)$ as a function of concentration of meropenem $(\mu \mathrm{M})$ in spiked human urine

\section{Selectivity of proposed method}

For the analytical application of proposed voltammetric method, the effect of some common excipients used in the pharmaceutical preparation was investigated. The tolerance limit was defined as the maximum concentration of interfering compound that results an error less than $5 \%$ for determination of meropenem. The effect of these compounds on voltammetric 
peak was carried by analysing samples solution containing fixed amount of meropenem $\left(1 \times 10^{-5} \mathrm{M}\right)$ spiked with various excess amount of each excipients under the same experimental conditions. The analysing results (Table 3) showed that the proposed method was able to assay meropenem in the presence of excipients, hence it can be considered selective and specific.

Table 3. Effect of various excipients on the voltammetric peak of $1 \times 10^{-5} \mathrm{M}$ meropenem

\begin{tabular}{lcc}
\hline Excipients, $1.0 \mathrm{mM}+$ Drug, $1 \times 10^{-5} \mathrm{M}$ & Potential observed & Signal change, $\%$ \\
\hline Only meropenem & 1.160 & 0 \\
Citric acid + Meropenem & 1.172 & 1.03 \\
Dextrose + Meropenem & 1.173 & 1.12 \\
Glucose+ Meropenem & 1.153 & 0.60 \\
Lactose+ Meropenem & 1.168 & 0.68 \\
Starch+ Meropenem & 1.161 & 0.08 \\
\hline
\end{tabular}

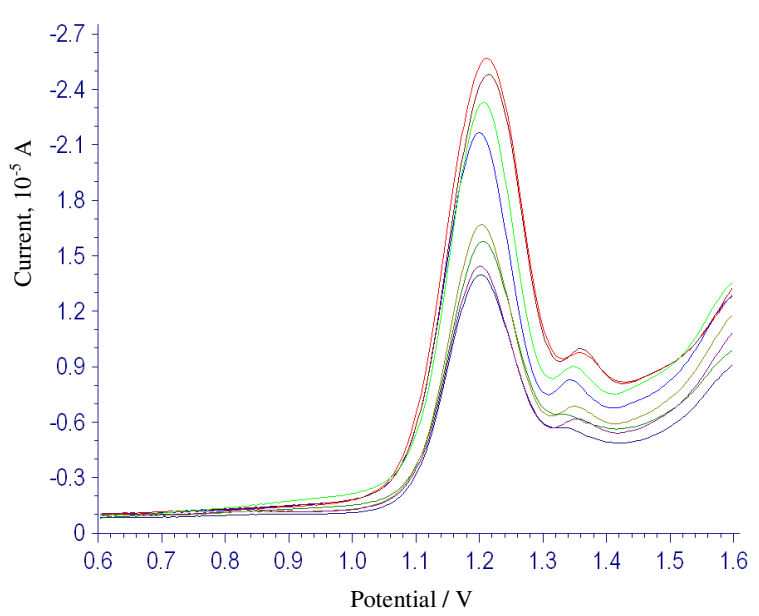

Figure 6(A). Square wave anodic adsorptive stripping voltammograms of different concentration of meropenem in spiked human serum at $\mathrm{pH} 6$

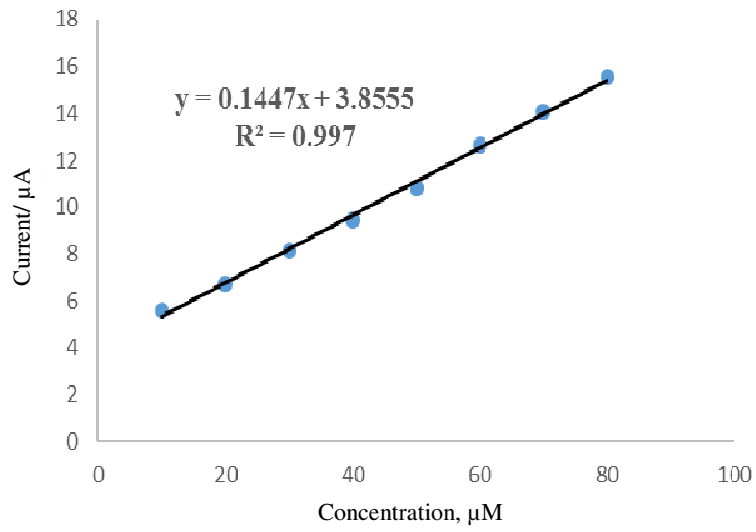

Figure 6(B). Plot of peak current $\left(i_{p} / \mu A\right)$ as a function of concentration of meropenem $(\mu \mathrm{M})$ in spiked human serum 


\section{Conclusion}

The electrochemical oxidation of meropenem in BR buffer at $\mathrm{pH}$ value 6 was investigated. The meropenem is irreversibly oxidized at high positive potentials. The proposed SWAAdSV technique for the determination of meropenem in spiked human urine and spiked serum samples was found to be as simple and rapid as the reported method and more selective, sensitive and validated than the reported method. The proposed voltammetric methods can be applied directly to the analysis of drug in body fluids. The proposed method is fully validated.

\section{Acknowledgment}

One of the authors Krishna Kumar Jhankal thankful to CSIR, New Delhi for providing financial assistance as SRF.

\section{References}

1. Birnbaum J, Kahan F M, Kropp H and Macdonald J S, Am J Med., 1985, 78(6), 3-21; DOI:10.1016/0002-9343(85)90097-X

2. Sunagawa M, Matsumura H, Inoue T, Fukasawa M and Kato M A, J Antibiot., 1990, XLIII, 519-532.

3. Satake S, Yoshihara E and Nakae T, J Antimicrob Chemother., 1990, 34, 6855690.

4. Edwards J R, J Antimicrob Chemother., 1995, 36, 1-17; DOI:10.1093/jac/36.suppl_A.1

5. $\quad$ Bompadre S, Ferrante L, Martinis M De and Leone L, J Chromatogr A, 1998, 812(12), 249-253; DOI:10.1016/S0021-9673(98)00249-0

6. Ehrlich M, Daschner F D and Kummerer K, J Chromatogr B, Biomedical Sciences Appl., 2001, 751(2), 357-363; DOI:10.1016/S0378-4347(00)00504-1

7. Ozkan Y, Kucukguzel I and Ozkan S A, Biomed Chromatogr., 2001, 15, 263-266; DOI:10.1002/bmc.68

8. Robatel C, Buclin T, Eckert P and Schaller M D, J Pharmac Biom Anal, 2002, 29(1-2), 17-33; DOI:10.1016/S0731-7085(02)00022-5

9. Mrestani Y, Neubert R and Nagel F, J Pharmac Biom Anal, 1999, 20(6), 899-903; DOI:10.1016/S0731-7085(99)00100-4

10. Taniguchi S, Hamase K, Kinoshita A and Zaitsu K, J Chromatogr B, 1999, 727(1-2), 219-225; DOI:10.1016/S0378-4347(99)00005-5

11. Al-Meshal M A, Ramadan M A, Lotfi K M and Shibl A M, J Clin Pharm Ther., 1995, 20(3), 159-163; DOI:10.1111/j.1365-2710.1995.tb00642.x

12. Kauffmann J M and Viré J C, Anal Chim Acta, 1993, 273(1-2), 329-334; DOI:10.1016/0003-2670(93)80173-I

13. Uslu B, Ozkan S A and Sentürk Z, Anal Chim Acta, 2006, 555(2), 341-347; DOI:10.1016/j.aca.2005.09.034

14. Kumari M and Sharma D K, J Korean Chem Soc., 2011, 55(1), 50-56; DOI:10.5012/jkcs.2011.55.1.050

15. Mourya G L, Jhankal K K, Parashar P and Sharma D K, Der Pharm Sinica, 2012, 3(6), 708-714.

16. Uslu B, Dogan B, Ozkan S A and Aboul-Enein S A, Anal Chim Acta, 2005, 552(1-2), 127-134; DOI:10.1016/j.aca.2005.07.040

17. Wang J, Electroanalytical Chemistry, Wiley-VCH Publication, New York, 167, 2006.

18. Bard A J and Faulkner L R, Electrochemical Methods: fundamentals and Applications, John Wiley \& Sons. Inc., New York, 2001. 
19. Kissinger $\mathrm{P} T$ and Heinman W R, Laboratory Techniques in Electroanalytical Chemistry, Marcel Dekker, New York, 1996.

20. Gosser D K, Cyclic Voltammetry, VCH, New York, 1993.

21. Ozkan S A, Uslu B and Aboul-Enein H Y, Crit Rev Anal Chem., 2003. 33(3), 155181; DOI:10.1080/713609162

22. Sharma D K, Mourya G L, Jhankal K K, Jones L A and Bhargava S K, Der Pharm Lettre, 2012, 4(5), 1599-1606.

23. Jhankal K K, Sharma A, Ramswaroop and Sharma D K, J Pharma Sci Res., 2015, 7(1), 10-13.

24. Sivaprasad M, Dhananjayulu M, and Jayapal M R and Sreedhar N Y, J Anal Bioanal Tech., 2014, 5(3), 192; DOI:10.4172/2155-9872.1000192

25. Laviron E, Roullier L and Degrand C J, J Electroanal Chem Interfacial Electrochem., 1980, 112(1), 11-23.

26. Niranjana E, Naik R R, Kumarswamy B E, Sherigara B S and Jayadevappa H, Int J Electrochem Sci., 2007, 2, 923.

27. Swartz M E and Krull I S, Analytical Method Development and Validation, Marcel Dekker, New York, 1997.

28. Sinha P, Shekhawat A and Sharma D K, Reports Electrochem., 2015, 5, 21-28; DOI:10.2147/RIE.S90750 